\begin{tabular}{|l|l|l||}
\hline \multicolumn{2}{|c|}{ PublisherInfo } \\
\hline \hline PublisherName & $:$ & BioMed Central \\
\hline \hline PublisherLocation & $:$ & London \\
\hline \hline PublisherImprintName & $:$ & BioMed Central \\
\hline \hline
\end{tabular}

\title{
Stromelysin-1 promotes mammary carcinogenesis
}

\begin{tabular}{|l|l|l||}
\hline \multicolumn{2}{|c|}{ ArticleInfo } \\
\hline \hline ArticleID & $:$ & 3627 \\
\hline \hline ArticleDOI & $:$ & $10.1186 /$ bcr-1999-66605 \\
\hline \hline ArticleCitationID & $:$ & 66605 \\
\hline \hline ArticleSequenceNumber & $:$ & 47 \\
\hline \hline ArticleCategory & $:$ & Paper Report \\
\hline \hline ArticleFirstPage & $:$ & 1 \\
\hline \hline ArticleLastPage & $:$ & 4 \\
\hline \hline & & RegistrationDate : 1999-8-17 \\
\hline ArticleHistory & $:$ & OnlineDate \\
\hline \hline ArticleCopyright & $:$ & Current Science Ltd1999-8-17 \\
\hline \hline ArticleGrants & $:$ & \\
\hline \hline ArticleContext & $:$ & 1305811 \\
\hline \hline
\end{tabular}




\section{Keywords}

extracellular matrix, matrix metalloproteinase, mammary gland, stromelysin, tumorigenesis

\section{Introduction}

Matrix metalloproteinases (MMPs) which degrade the extracellular matrix (ECM) are invariably upregulated in the stromal compartment of epithelial cancers and appear to promote tumor invasion, angiogenesis and metastasis. MMP-3/stromelysin-1 (Str1) is a stromal MMP that may permit oncogenesis by the degradation of numerous ECM substrates. The gene encoding Str1 was originally cloned, and has since been repeatedly recloned, as a tumor-specific gene.

In the mouse, Str1 is expressed in stromal cells during mammary development during both ductal branching and ECM remodeling, following cessation of lactation and alveolar regression.

\section{Aims}

To examine the effect of Str1 on tumorigenesis in mouse mammary epithelial cells both in vitro and in vivo.

\section{Comments}

The finding that an MMP, Str1, is capable of inducing tumorigenesis in the absence of carcinogens or pre-existing mutations is important. Of further interest is that its transient expression suffices to initiate the tumorigenic process, at least in an immortalized cell line. These results flag up once again the importance of the stromal microenvironment in control of gene expression, and show that its remodelling by MMPs may result in genomic instability that is likely to affect neoplastic progression. The novel genetic loci particularly associated with the EMT phenotype may yield pathways downstream from Str 1 and define new molecular targets for treatment of aggressive breast cancers. 


\section{Methods}

The effect of Str1 on tumor progression is addressed using exogenous recombinant Str1 on an immortalized mouse mammary cell line in vitroand two genetic approaches: phenotypically normal, immortalized, mouse mammary epithelial cells that express Str1 controlled by an inducible promoter, and mice with an Str1 transgene targeted to mouse mammary glands by the mouse whey acidic protein (WAP) gene promoter.

\section{Results}

Treatment of the immortalized mouse mammary epithelial cell line Scp2 in vitro with exogenous recombinant Str1 rapidly induced an epithelial-to-mesenchymal cell transition (EMT). EMT is characterized by loss of cell-cell interactions, acquisition of a scattered morphology, downregulation of epithelial cytokeratins, and upregulation of the mesenchymal marker vimentin.

Using the second approach, it was found that Scp2 cells transfected with Str1 controlled by an inducible promoter undergo EMT when induced and can also form anchorage-independent colonies in agar. In the absence of Str1 expression, Scp2 cells transplanted into cleared mammary fat pads form duct-like structures. When Str1 gene expression is induced, EMT is triggered and cells become tumorigenic and invasive in vivo. Once triggered, repression of Str1 expression could not reverse their tumorigenicity.

To examine the long-term effects of Str1 on normal mammary epithelial cells in vivo, WAP-Str1 transgenic mice were used. At age 6-24 months, such mice develop mammary abnormalities, premalignant lesions and tumors. Less than one in ten mice examined had a mammary tumor and the average latency was 18 months. Hyperplastic lesions were apparent in half of the animals at six months and in three-quarters at two years, consistent with a multistage neoplastic progression induced by Str1 expression. In total, twelve tumors were seen, of which nine were well differentiated and three were undifferentiated with evidence of EMT.

Microdissection and comparative genome hybridization (CGH) revealed that tumors exhibiting EMT contained DNA copy number gains on chromosome 15, specifically in fibroblast-like areas of the tumor.

\section{Discussion}

Neoplastic changes arose in WAP-Str1 mice without carcinogens or pre-existing mutations, but were not present in the absence of WAP-Str1 expression, and were quenched by TIMP-1 expression. 
Str1 expression appears to be associated with EMT, a phenotype common in both embryonic development and wound repair. The most aggressive human breast cancers undergo EMT with loss of Ecadherin, co-expression of cytokeratins and vimentin, and expression of MMPs normally confined to the stromal component.

The authors favor the hypothesis that MMPs foster tumorigenicity by triggering the E-cadherin/betacatenin pathway which is linked to EMT, invasion and genomic instability. It is conceivable that, through the alteration of cellular adhesion. MMPs could affect cell cycle checkpoints and promote genomic instability leading to the consistent DNA copy number gains that were seen in lesions in the Str1-transgenic mice.

Thus, the results indicate that Str1 can promote early neoplastic changes, stereotyped genomic changes and late phenotypic conversions associated with aggressive tumor behavior, and support the hypothesis that an altered stromal environment can promote tumorigenesis.

\section{References}

1. Sternlicht MD, Lochter A, Sympson CJ, Huey B, Rougier JP, Gray JW, Pinkel D, Bissell MJ, Werb Z: The stromal proteinase MMP3/stromelysin-1 promotes mammary carcinogenesis. Cell. 1999, 98: 137-146. 